\title{
LA CIUDAD: \\ Sugerencias para la investigación \\ de la conducta humana en un ambiente urbano ${ }^{1}$
}

\author{
Robert E. Park
}

\begin{abstract}
Nota introductoria
Continuando con el programa de difusión de los clásicos del pensamiento social, la Revista Colombiana de Educación ofrece ahora el texto fundacional de la sociología urbana. Publicado originalmente en 1915 y reimpreso diez años después en el volumen colectivo La ciudad, se convirtió al momento en el punto de partida de los investigadores de la vida metropolitana. Su autor, Robert Ezra Park (1864-1944), una de las grandes figuras de la sociología norteamericana y uno de los más renombrados paladines de la escuela de Chicago, aísla con habilidad analítica los puntos focales del examen sociológico de la ciudad. Para Park los centros urbanos poseen una cultura propia y su dinámica expresa las tensiones y conflictos más significativos del mundo contemporáneo. No sólo concentran o tienden a concentrar la mayoría de la población de un país, sino que en su interior se 'desarrollan las instituciones más representativas de la sociedad moderna, entre las cuales los establecimientos educativos no son los menos significativos. Junto a la iglesia, la policía y los tribunales, cumplen una notable función de control social y en muchos aspectos asumen las tareas tradicionalmente adscritas a la institución familiar. A diferencia del pasado, ahora los adultos van al trabajo y dejan a la escuela y a su personal especializado la tarea de cuidar, formar y orientar a sus vástagos. Hasta donde se tiene noticia, esta publicación constituye la primera versión castellana del legendario ensayo de Park sobre la vida urbana. G.C.
\end{abstract}

La ciudad, desde el punto de vista de este ensayo, es algo más que un agregado de individuos y servicios sociales, calles, edificios, iluminación pública, tranvías, teléfonos, etc.; algo más, también, que una simple constelación de instituciones y aparatos administrativos tribunales, hospitales, escuelas, estaciones de policía, dependencias múltiples. La ciudad es, por el contrario, un estado mental, un cuerpo de costumbres y tradiciones, de actitudes y sentimientos inherentes a dichas costumbres y transmitidos mediante dichas tradiciones. En otras palabras, la ciudad no es tan sólo un mecanismo físico o una construcción artificial, ya que está implicada en los procesos vitales de quienes viven en ella; es un producto de la naturaleza y de la naturaleza humana en particular.

La ciudad tiene, como hace poco lo señaló Oswald Spengler, su propia cultura: "lo que la choza es para el campesino, lo es la ciudad para el hombre civilizado. Así como aquélla tiene sus dioses protectores, la ciudad tiene su deidad protectora, su santo local. La ciudad, al igual que la choza del campesino, hunde sus raíces en el suelo."

Recientemente la ciudad ha sido estudiada desde el punto de vista de su geografía, y últimamente desde el punto de vista de su ecología. Dentro de los límites de la comunidad urbana -y en efecto, dentro de los límites de cualquier área natural de habitación humana-hallamos fuerzas en marcha que tienden a producir un agrupamiento típico y

\footnotetext{
1 Tomado de Robert E. Park et al. The City. (Chicago: Chicago University Press, 1925). Traducción de Alberto Henao, profesor del Departamento de Sociología de la Universidad Nacional de Colombia.

${ }^{2}$ Oswald Spengler. Der Untergang des Abendlandes (München 1922), IV, 105.
} 
ordenado de su población e instituciones. La ciencia que se encarga de analizar estos factores y de explicar las constelaciones típicas de personas e instituciones producidas por la cooperación de tales fuerzas es la ecología humana, que se diferencia de aquélla que estudia a las plantas y a los animales.

El transporte y la comunicación, los tranvías y los teléfonos, los periódicos y la publicidad, los edificios de acero y los ascensores en fin, todas las cosas que tienden a producir, en conjunto, una mayor movilidad y una mayor concentración de la población urbana son los factores primarios de la organización ecológica de la ciudad.

Sin embargo, la ciudad no es tan sólo una unidad geográfica y ecológica; es al mismo tiempo, una unidad económica basada en la división del trabajo. La multiplicación de ocupaciones y oficios de la población es uno de los más notables, pero uno de los aspectos menos comprendidos de la moderna vida urbana. Desde este punto de vista, podemos pensar la ciudad como un todo orgánicamente relacionado, es decir, un lugar y un pueblo con sus industrias y sus aparatos administrativos que forma un tipo de mecanismo psicofísico en el cual y a través del cual los intereses privados y políticos hallan no sólo su expresión colectiva sino también corporativa.

Muchas de las cosas que generalmente se identifican con la ciudad sus reglamentaciones, su organización formal, sus edificios, su red vial son o parecen ser un mero artefacto. Pero estas cosas, en sí mismas accidentales, se vuelven parte de la vida urbana cuando y sólo cuando a través del uso y la costumbre se conectan, como la herramienta en manos del hombre, con las fuerzas vitales que poseen los individuos y las comunidades.

Finalmente, la ciudad es el hábitat natural del hombre civilizado. Por esta razón es un área cultural caracterizada por su propio y peculiar tipo de cultura:

"Es absolutamente cierto - dice Spengler- que todas las grandes culturas han sido urbanas. El soberbio hombre de la segunda generación es un animal urbanizador. Este es el criterio que rige a la historia mundial, y que la diferencia de la historia de la humanidad: la historia mundial es la de los hombres de ciudad. Las naciones, los gobiernos, la política y la religión, todos ellos descansan sobre el fenómeno básico de la existencia humana, la ciudad." ${ }^{3}$

La antropología, la ciencia del hombre, se ha interesado hasta ahora, sobre todo, por el estudio de los pueblos primitivos. Pero el hombre civilizado es también un objeto interesante de investigación, pues lleva una vida más abierta a la exploración y estudio. Aunque la vida y la cultura urbanas son más variadas, más sutiles, más complicadas, ambos terrenos podrían estudiarse con la misma perspectiva. El método de observación que con tanta paciencia han utilizado antropólogos como Boas y Lowie para registrar la vida y las costumbres de los indígenas norteamericanos, podría servir también, quizá de manera más fructífera, para estudiar las costumbres, las creencias, las prácticas sociales y las concepciones de vida prevalecientes en la Pequeña Italia o en la parte baja del North Side de Chicago, o para dar cuenta de las sofisticadas tradiciones de los habitantes del Greenwich Village o del Washington Square de New York.

Estamos en deuda con aquellos novelistas que nos han aportado un conocimiento íntimo de la vida urbana contemporánea, pero para entenderla cabalmente necesitamos

\footnotetext{
${ }^{3}$ Oswald Spengler, Untergang des Abendlandes, IV, 106.

Digitalizado por RED ACADEMICA
} 
mucho más que el legado de Emilio Zola en sus novelas "experimentales" y en los anales de la familia RougonóMacquart. Tenemos que ir más allá, aunque sólo sea para poder leer de manera inteligente los periódicos. La razón por la cual la crónica diaria es tan impactante, y tan fascinante, es que el lector promedio sabe muy poco sobre los hechos vitales que registra la prensa.

Las observaciones que siguen a continuación pretenden definir un punto de vista e indicar un programa para el estudio de la vida urbana: su organización física, sus ocupaciones y oficios, y su cultura.

\section{El plan urbano y la organización local}

La ciudad, particularmente la ciudad moderna de los Estados Unidos, nos sorprende porque a primera vista no parece el producto de un proceso de desarrollo natural, y es difícil reconocerla como un entidad viva. El plan físico de la mayoría de las ciudades norteamericanas se parece a un tablero de ajedrez. La unidad de distancia es la cuadra. Esta forma geométrica sugiere que la ciudad es una construcción puramente artificial que podría trasladarse de un lugar a otro, como podría hacerse con una casa.

Sin embargo, la ciudad está arraigada en los hábitos y costumbres de la gente que la habita. Como consecuencia, posee una moral tanto como una organización física, y ambas interactúan mutuamente de manera característica moldeándose y modificándose entre sí. Es la estructura de la ciudad lo que primero nos impresiona por su visible vastedad y complejidad, pero esta estructura tiene su fundamento, ante todo, en la naturaleza humana de la cual es su expresión. Esta vasta organización que ha surgido como respuesta a las necesidades de sus habitantes, una vez formada, se les impone como un fenómeno externo, y a su vez los forma de acuerdo con los propósitos y los intereses incorporados por ella. La estructura y la tradición no son sino aspectos diferentes de un complejo cultural único que determina lo que es característico y peculiar a la ciudad en comparación con la vida de los pequeños poblados y de las áreas rurales.

El plan de la ciudad. - Puesto que la ciudad tiene una vida propia, hay un límite a las modificaciones arbitrarias que podrían hacerse tanto (1) a su estructura física, como (2) a su orden moral.

El plan de la ciudad, por ejemplo, establece medidas y límites, determina de manera general la ubicación y el carácter de las construcciones e impone una distribución ordenada de aquellos edificios que son erigidos por iniciativa privada o por disposición gubernamental. Sin embargo, dentro de los límites prescritos, el inevitable despliegue de la naturaleza humana va dándole a estas áreas, y a las construcciones mismas, un carácter propio que es menos fácil de controlar. Por ejemplo, bajo nuestro sistema de propiedad particular no es posible determinar por adelantado el tamaño de las áreas donde se concentrará una población dada. La ciudad no puede fijar el valor de la tierra, y dejamos a la iniciativa empresarial, en la mayoría de los casos, la tarea de determinar los límites urbanos y la ubicación de los distritos residenciales e industriales. Los gustos personales y la conveniencia, los intereses económicos y vocacionales infaliblemente tienden a segregar, a clasificar las poblaciones de las grandes urbes. De esta manera, la ciudad adquiere una organización y distribución de la población que no es fruto de un diseño artificial ni puede ser sometida a su control.

Particularmente en New York y en Chicago, la Bell Telephone Company ha emprendido serias investigaciones, cuyo propósito es determinar por adelantado el probable desarrollo y distribución de la población urbana en las áreas metropolitanas. La Sage Foundation, en 
el curso de sus estudios sobre planeación urbana, trató de encontrar una fórmula matemática que le permitiera predecir la futura expansión y los límites poblaciones de la ciudad de New York. El reciente desarrollo de los almacenes de cadena ha convertido el problema de ubicación en un asunto que preocupa a las diferentes corporaciones involucradas en tal negocio.

El resultado ha sido el surtimiento de una nueva profesión. Tenemos ahora una nueva clase de expertos cuya única ocupación es descubrir y ubicar, con cierta precisión científica, aquellos restaurantes, cigarrerías, droguerías, y otro tipo de pequeños establecimientos cuyo éxito depende en gran medida de su ubicación. El negocio de bienes raíces con mucha frecuencia está interesado en financiar negocios locales de esta clase en sitios donde se cree que serán rentables, aceptando como parte de la renta un porcentaje de las utilidades.

La geografía, las ventajas y desventajas naturales, inclusive los medios de transporte, determinan con anterioridad el esbozo general del plan urbano. A medida que la ciudad incrementa su población, las influencias sutiles de la simpatía, de la rivalidad y de la necesidad económica tienden a controlar su distribución. Los negocios y las industrias tratan de encontrar sitios favorables y estimulan a algún sector de la población para que se establezca a su alrededor. De esta forma crean zonas residenciales de las cuales las clases pobres son excluidas debido al incremento en el valor de la tierra. Esto ocasiona el desarrollo de barrios bajos habitados por esas clases, incapaces de defenderse del acoso producido por el abandono y los vicios.

Con el transcurso del tiempo cada sector, cada barrio, adquiere algo del carácter y de las cualidades de sus habitantes y cada parte de la ciudad asume rasgos que expresan sus sentimientos peculiares. Como resultado, lo que al principio era una simple distribución geográfica se convierte en un vecindario, es decir, en una localidad con sentimientos, tradiciones e historia propia. En su interior, de algún modo, se mantiene la continuidad de los procesos históricos donde el pasado se impone sobre el presente y la vida de cada localidad se desenvuelve con un ritmo propio, más o menos independiente del gran círculo de vida e intereses que la rodea.

La organización de la ciudad, el carácter de su ambiente y de la disciplina que impone, están determinados en última instancia por el tamaño de la población, su concentración y distribución en el área urbana. Por esta razón es importante estudiar el desarrollo de la ciudad y comparar la idiosincrasia derivada de la distribución poblacional. Algunas de las primeras cosas que quisiéramos saber sobre la ciudad son, por consiguiente, estas:

¿Cuáles son las fuentes de la población urbana?

¿Qué parte de su crecimiento poblaciones es normal, es decir, el número de nacimientos sobre el número de muertes?

¿Qué parte se debe a migración (a) de nativos? (b) de extranjeros?

¿Cuáles son las áreas "naturales" más sobresalientes, es decir, las áreas de segregación de la población?

¿Cómo se afecta la distribución de la población urbana por (a) los intereses económicos y el valor de la tierra, (b) los intereses sentimentales, la raza, la vocación, etc.? 


\section{¿Dónde está declinando la población? ¿Dónde se está expandiendo?}

¿Dónde podemos correlacionar el desarrollo de la ciudad y el tamaño de las familias con nacimientos y muertes, matrimonios y divorcios, arriendos y patrones de vida?

El vecindario.-La proximidad y el contacto vecinal son los fundamentos de la forma de asociación más simple y elemental que encontramos en la organización de la vida urbana. Los intereses locales y las asociaciones alimentan el sentimiento local y, bajo un sistema de participación política basado en la residencia, el barrio se vuelve la base del control político conviniéndose así en la más pequeña unidad social y política de la ciudad.

Desde la antigüedad, uno de los hechos sociales más notables consiste en entender que el hombre que se establece al lado de los suyos comienza a interesarse en desplegar su sentido de camaradería ... El barrio es una unidad social que, gracias a la clara definición de sus límites, a su integridad orgánica interior, a sus reacciones emotivas, puede considerarse, con justicia, como algo que funciona a la manera de una mente social ... El jefe local, no importa cuán autocrático puede ser en la esfera más amplia de la ciudad gracias al poder que extrae del vecindario, debe siempre ser del y para el pueblo; y siempre se cuida de no engañar a los vecinos al menos en lo que atañe a sus intereses locales. Es muy difícil burlarse de un vecindario cuando sus propios asuntos están en juego. ${ }^{4}$

El vecindario existe sin una organización formal. Las sociedades de mejoramiento local son estructuras derivadas de la organización espontánea de vecinos para darle expresión al sentimiento y a los intereses locales.

Bajo las complejas influencias de la vida urbana, lo que puede llamarse el sentimiento vecinal normal ha llevado a cabo muchos cambios curiosos e interesantes, y producido muchos tipos inusitados de comunidad local. Hay barrios nacientes y vecindarios en proceso de disolución. Consideremos por ejemplo, la Quinta Avenida de Nueva York, que rápidamente se ha ido convirtiendo en una comunidad altamente organizada e íntima y que probablemente nunca tuvo una asociación de mejoras, y comparémosla con la Calle 135 en el Bronx (donde la población negra está probablemente más concentrada que en cualquier otra parte del mundo).

En la historia de Nueva York el significado del nombre Harlem ha cambiado del holandés al irlandés, luego al judío y posteriormente al negro. Este último cambio se ha producido más rápidamente. A lo largo de la América negra, desde Massachusetts hasta el Mississippi y desde allí hasta Los Ángeles y Seattle, este nombre, que hace quince años apenas se oía, ahora representa a la metrópolis negra. En efecto, Harlem es, por la atracción que ejerce sobre cada isla del Caribe y sobre el África misma, la gran Meca para quien busca paisaje y placer, para el curioso, el aventurero, el empresario, el ambicioso y el talentoso del mundo negro. ${ }^{5}$

Es importante saber cuáles son las fuerzas que tienden a disolver los intereses y los sentimientos que dotan al vecindario de su carácter individual. En términos generales,

\footnotetext{
${ }^{4}$ Robert A. woods, "The Neighborhood ip Social Construction", Papers and Proceedings of the Eight Annual Meeting of the American Sociological Society, 1913

5 James Welden Johnson, "The Making of Harlem”, Survey Graphic, Marzo 1, 1925.
} 
podría decirse que tales fuerzas están constituidas por todo aquéllo que crea inestabilidad en la población y dispersa su atención en un amplio rango de intereses.

\section{¿Qué parte de la población es flotante?}

¿De qué elementos, es decir, razas, clases, etc., está compuesta dicha población?

¿Cuánta gente vive en hoteles, apartamentos y espacios multifamiliares?

¿Cuánta gente posee su propia vivienda?

¿Qué proporción de la población está compuesta por nómadas, hobos ${ }^{6}$, gitanos? $^{2}$

Ciertos vecindarios tienen que padecer el aislamiento. En diversas oportunidades se han hecho esfuerzos por reconstruirlos y revivir-los restableciendo sus lazos con los intereses más amplios de la comunidad. Tal ha sido, en parte, el propósito de los asentamiento sociales. Estas organizaciones, entre otras que intentan reconstruir la vida urbana, han desarrollado ciertos métodos y técnicas para estimular y controlar a las comunidades locales. Debiéramos estudiar esos métodos y esas técnicas puesto que lo que permite revelar la naturaleza esencial de un objeto es precisamente el método por medio del cual lo controlamos y lo hacemos predecible (Gesetzmässigkeit). ${ }^{7}$

En muchas ciudades europeas, y en algunas de este país, la reconstrucción de la vida urbana ha conducido a la construcción de jardines en los suburbios y a reemplazar edificios insalubres y en ruinas por otros bajo la propiedad y el control de la municipalidad.

En las ciudades de los Estados Unidos se ha intentado renovar vecindarios degradados mediante la construcción de sitios deportivos a partir de la introducción supervisada de diversos deportes, o a través de la creación de grupos de danzas en teatros de propiedad municipal. Éstas y otras mediadas para elevar el tono moral de las poblaciones segregadas de las grandes ciudades, debieran estudiarse como parte de la investigación sobre el vecindario en general y, en especial, por lo que podrían revelarnos sobre la conducta y la naturaleza humanas.

Colonias y áreas segregadas._En el ambiente urbano el vecindario va perdiendo el significado que poseía en las formas más simples y primitivas de la sociedad. El desarrollo de los medios de comunicación y de transporte, que le permiten al individuo distribuir su atención y vivir al mismo tiempo en diferentes mundos, tiende a destruir la permanencia y la intimidad del barrio. Sin embargo, allí donde existe el prejuicio racial, el aislamiento de las colonias raciales y de inmigrantes en los llamados ghettos y áreas de segregación permite que se preserven y se intensifiquen la intimidad y la solidaridad de

\footnotetext{
6 Hobo' significa tanto «trabajador ocasional y migratorio» como «vagabundo». Mantenemos la palabra inglesa pues no existe en español un término equivalente para definir a este tipo social. (Nota del Traductor).

${ }^{7}$ De ahí que si queremos emplear la palabra (naturaleza) como un término lógico en la teoría de la ciencia, debamos decir que naturaleza es la realidad considerada en su conexión conforme a ley. Hallamos este significado, por ejemplo, en la expresión ley natural. Empero, en lo que transita a los conceptos también podemos denominarlo la naturaleza de los objetos, o expresándonos con la mayor brevedad: la naturaleza es la realidad teniendo en cuenta lo general. Entonces el término obtiene ante todo un significado lógico" ( $\mathrm{H}$. Rickert, Límites de la formación de conceptos en las ciencias naturales).
} 
los grupos vecinales. No obstante, donde individuos de la misma raza o del mismo oficio viven juntos en grupos segregados, el sentimiento vecinal puede fusionarse con los antagonismos raciales y los intereses de clase.

Las distancias físicas y sentimentales se refuerzan entre sí, y la distribución local de la población y las diferencias de clase y de raza actúan conjuntamente para influenciar la evolución de la organización social. Toda gran ciudad tiene sus colonias raciales, como los China-towns de San Francisco y Nueva York, o la Pequeña Sicilia de Chicago. Adicionalmente, la mayor parte de las ciudades tienen sus propios subdistritos segregados, como aquél que hasta hace poco existió en Chicago, y que era sitio de reunión de todo tipo de criminales. Toda gran ciudad tiene sus propios suburbios ocupacionales, como el Stockyards de Chicago, y sus enclaves residenciales, como Brookline en Boston, el llamado "Gold Coast" en Chicago, el Greenwich Village en Nueva York, cada uno de los cuales tiene el tamaño y el carácter de un pueblo completamente separado, salvo que su población está segregada. Indudablemente el más destacado ejemplo de una ciudad dentro de la ciudad es el East London, con una población de dos millones de trabajadores, compuesta por personas de la misma raza, o de diferentes razas pero de la misma clase social.

La gente que originalmente formó el East London se ha dispersado y cruzado el Lea, ocupando los pantanos y las praderas del otro lado. Esta población ha creado sus propios pueblos que antenormente fueron simples villas rurales: West Ham, con una población de 300 mil; East Ham, con 90 mil; Stratford y sus "hijos" con 150 mil; y otros "caseríos" igualmente grandes. Incluyendo estas nuevas poblaciones, tenemos un agregado de alrededor de dos millones de personas, una población mayor que la de Berlín, Viena, San Petersburgo o Filadelfia.

Aunque es una ciudad llena de templos y lugares de adoración, todavía no existe ninguna catedral, ya sea Anglicana o Romana; cuenta con un buen servicio de escuelas elementales pero no tiene ninguna secundaria ni tampoco universidades $o$ escuelas superiores; toda la gente lee los periódicos pero no existe ninguno de carácter local. En las calles nunca se ha visto un carruaje particular; no existe ningún barrio elegante; uno no encuentra ninguna mujer en las calles principales. La gente, las tiendas, las casas, el transporte, todo tiene el inequívoco sello de la clase trabajadora.

Quizá la cosa más extraña sea ésta: en una ciudad de dos millones de personas ¡no hay hoteles! Esto significa, por supuesto, que no hay visitantes. ${ }^{8}$

En las viejas ciudades europeas, donde el proceso de segregación ha ido lejos, las distinciones entre vecindarios probablemente están más marcadas que en los Estados Unidos. El East London es una ciudad de una sola clase social, pero dentro de sus límites la población está segregada por intereses raciales, culturales y ocupacionales. El sentimiento de vecindad, profundamente arraigado en la tradición y en las costumbres locales, ejerce una influencia decisiva y selectiva sobre la población de las viejas ciudades europeas, lo que se comprueba fácilmente por las marcadas diferencias entre sus habitantes.

${ }^{8}$ walter Besant, East London, pp. 7-9. 
Lo que pretendemos conocer de estos vecindarios, comunidades raciales y áreas segregadas que existen dentro o alrededor de los límites de las grandes ciudades, es lo mismo que quisiéramos saber de todos los grupos sociales:

¿Cuáles son los elementos que los componen?

¿Hasta dónde son el producto de procesos de selección?

¿Cómo se entra y se sale de estos grupos?

¿Cuál es la permanencia y estabilidad relativas de su población?

¿Cuáles son sus características sociales?

¿Cuántos niños nacen allí y cuántos permanecen?

¿Cuál es la historia del barrio? ¿Qué hay en su subconsciente en la experiencia adormecida u olvidada que determine sus sentimientos y actitudes?

¿Qué existe en ellos de manera clara y consciente, es decir, cuáles son sus sentimientos y doctrinas declaradas?

¿Qué dan por sentado? ¿Qué consideran novedoso? ¿Qué concita la atención general? ¿Qué modelos, internos o externos, imitan?

¿En qué consisten los rituales sociales, es decir, qué cosas deben hacerse diariamente en el barrio para evitar ser mirado como un individuo peculiar?

¿Quiénes son sus líderes? ¿Qué intereses representan y cuál es la técnica a través de la cual ejercen control?

\section{La organización industrial y el orden moral}

La ciudad antigua fue primariamente una fortaleza, un lugar de refugio en tiempos de guerra. La ciudad moderna, por el contrario, es ante todo un sitio de comercio, y debe su existencia al mercado a cuyo alrededor se fue desarrollando. La competencia industrial y la división del trabajo, responsables en buena parte del desarrollo de las potencialidades latentes de la humanidad, son posibles únicamente bajo la condición de la existencia de mercados, de dinero, y de todo aquello que facilita el intercambio y el comercio.

Un viejo adagio alemán dice: el aire de la ciudad hace libres a los hombres (Stadt Luft macht frei). Esta es sin duda una referencia a los días en que las ciudades libres de Alemania disfrutaban del patronaje del emperador y las leyes permitían que un siervo fugitivo se convirtiera en hombre libre si podía arreglárselas para respirar el aire de la ciudad por un año y un día. Sin embargo, la ley, por sí misma, no hubiera podido liberar al artesano. Un mercado abierto en el cual pudiera vender sus productos así como la aplicación de la economía monetaria a las relaciones entre él y su amo completaron su emancipación.

Clases y tipos vocacionales. - El viejo adagio que describe a la ciudad como el ambiente natural del hombre libre, es cierto en la medida en que el individuo encuentra allí las oportunidades, la diversidad de intereses y tareas y la cooperación vasta aunque inconsciente para escoger su propia vocación y desarrollar sus peculiares talentos. La 
ciudad ofrece un mercado para los talentos especiales del individuo. La competencia personal tiende a seleccionar para cada tarea al individuo que está mejor dotado para realizarla.

La diferencia de talentos naturales entre los hombres es, en realidad, mucho menor de lo que creemos; y la diversidad de habilidades que parece distinguir en la edad madura a los hombres de diferentes profesiones, en la mayoría de los casos no es la causa sino el efecto de la división del trabajo. La diferencia entre las aptitudes más disímiles, entre un filósofo y un portero, por ejemplo, parece no provenir de la naturaleza, sino del hábito, de las costumbres, de la educación. Cuando llegaron al mundo, y durante los primeros seis $u$ ocho años de su existencia, probablemente fueron muy similares y ni sus padres ni sus compañeros de juego podrían haber percibido alguna notable diferencia entre ellos. A esa edad, o un poco después, son empleados en diferentes ocupaciones y entonces la diferencia de talento empieza a notarse y a ampliarse hasta tal punto que el filósofo, en su vanidad, no desearía reconocer ningún parecido con el portero. Pero sin la disposición a conducir carruajes, o al intercambio de productos, todos los hombres se habrían procurado la satisfacción de sus necesidades. Todos habrían tenido los mismos deberes y el mismo trabajo y no habrían existido diferencias de empleo que pudieran haber ocasionado grandes diferencias de talento.

En la medida en que es el poder de intercambio el que da ocasión a la división del trabajo, así también la amplitud de esta división debe siempre estar limitada por el grado de tal poder o, en otras palabras, por el grado de desarrollo del mercado. Hay cierto tipo de actividades, incluyendo las de más bajo nivel, que no pueden llevarse a cabo sino en las grandes ciudades. ${ }^{9}$

El éxito, bajo las condiciones de competencia personal, depende de la concentración en una tarea singular, y esta concentración estimula la demanda de métodos racionales, instrumentos técnicos y habilidades excepcionales. La habilidad excepcional, aunque basada en el talento natural, requiere especial preparación y ha originado la creación de escuelas de comercio y de oficinas dedicadas a la orientación profesional. Todo ello, directa o indirectamente, sirve para seleccionar y subrayar las diferencias individuales.

Cualquier mecanismo que facilite el comercio y la industria prepara el camino para una adicional división del trabajo y, así, tiende a especializar en mayor medida las tareas en las cuales los hombres hallan su vocación.

El resultado de este proceso es la ruptura o modificación del viejo orden social, de aquella forma de organización económica basada en los lazos familiares, en las asociaciones locales, en la cultura, en la casta y el status para dar paso a una organización que se fundamenta en la ocupación y en los intereses vocacionales.

En la ciudad, cada vocación, incluso la de mendigo, tiende a asumir el carácter de una profesión y la disciplina que el éxito en cualquier vocación impone, junto con las asociaciones que de ella se derivan, enfatizan esta tendencia, es decir, la tendencia no únicamente a la especialización sino a racionalizar dicha ocupación y a desarrollar una técnica consciente y específica para llevarla a cabo.

\footnotetext{
${ }^{9}$ Adam Smith, La Riqueza de las Naciones. pp. 28-29. 
En primera instancia, las vocaciones y la división del trabajo producen no tanto grupos sociales como tipos profesionales: actor, plomero, leñador. Organizaciones como los sindicatos de trabajadores o las asociaciones de comerciantes, se basan en los intereses comunes $\mathrm{y}$, en tal sentido, se diferencian de otras formas de asociación como el barrio, cuyo soporte es la contigüidad, la vinculación personal y los lazos comunes de solidaridad. Las diferentes actividades y profesiones parecen destinadas a agruparse en clases, por ejemplo artesanos, industriales, profesionales. Pero en el moderno estado democrático, las clases no han alcanzado formas eficaces de organización. El socialismo, que se esfuerza por crear una organización afincada en la "conciencia de clase" no ha podido crear algo distinto de un partido político salvo, quizá, en Rusia.

La división del trabajo, en tanto que disciplina, es decir, en tanto que medio para moldear el carácter, puede entonces estudiarse mucho mejor a través de los tipos vocacionales que produce: la vendedora, el policía, el buhonero, el taxista, el celador, el clarividente, el actor de vaudeville, el curandero, el cantinero, el jefe de barrio, el esquirol, el agitador laboral, el maestro de escuela, el reportero, el corredor de bolsa, el jardinero, el prestamista. Todos ellos son productos característicos de la vida urbana; cada uno de ellos, con su experiencia personal, sus conocimientos y puntos de vista, determina tanto la propia individualidad de cada grupo profesional como de la ciudad como un todo.

¿Hasta qué punto el grado de inteligencia representado por los diferentes oficios y profesiones depende de la habilidad natural?

¿Hasta qué punto está determinada la inteligencia por el carácter de la ocupación y las condiciones bajo las cuales se practica?

¿Hasta qué punto el éxito en tales ocupaciones depende del buen juicio y del sentido común? ¿Hasta qué punto de la habilidad técnica?

¿El éxito en las diferentes vocaciones está determinado por la habilidad natural o por el entrenamiento?

¿Qué tipo de prestigio y qué clase de prejuicios son inherentes a cada oficio y profesión y por qué?

¿Está determinada la elección de una ocupación por consideraciones temperamentales, económicas o sentimentales?

¿En qué clase de ocupaciones tienen los hombres más éxito que las mujeres yio viceversa y por qué?

¿En qué medida es la ocupación, antes que la asociación, responsable de las actitudes mentales y de las predilecciones morales? ¿Sostienen las mismas opiniones quienes desempeñan la misma profesión u oficio, a pesar de representar diferentes nacionalidades y diferentes grupos culturales?

¿Hasta qué punto el credo político o social socialismo, anarquismo, sindicalismo, etc., está determinado por la ocupación o por el temperamento?

¿Hasta qué punto la doctrina social y el idealismo social han reemplazando a la fe religiosa en las diferentes ocupaciones y por qué? 
¿Tienden a asumir las clases sociales el carácter de grupos culturales? En otras palabras, ¿tienden las clases a adquirir el carácter excluyente e independiente propio de las castas y nacionalidades? $\mathrm{O}$, ¿cada clase social siempre depende de la existencia de su clase opuesta?

\section{¿Hasta qué punto siguen los hijos la vocación de sus padres y por qué?}

¿Hasta qué punto se mueven los individuos de una clase a otra y cómo este hecho modifica el carácter de las relaciones de clase?

Las noticias y la movilidad del grupo social._La división del trabajo, en la medida en que hace que el éxito individual dependa de la concentración en una tarea específica, ha tenido el efecto de acrecentar la interdependencia entre las diferentes vocaciones. Se crea así una organización social en la que los individuos llegan a ser cada vez más dependientes de la comunidad de la cual son parte integrante. El efecto de esta creciente interdependencia de las partes, bajo condiciones de competencia personal, es el de crear en la organización industrial un cierto tipo de solidaridad social, pero una solidaridad basada no en el sentimiento o el hábito sino en la comunidad de intereses.

En el sentido en que aquí los usamos, sentimiento es un término más concreto en tanto que interés es más abstracto. Podemos tener un sentimiento de aprecio por una persona, un lugar o un objeto cualquiera. Puede ser un sentimiento de aversión o uno de posesión. Pero decir que se está poseído por un sentimiento hacia algo, significa que se es incapaz de actuar hacia aquéllo de una manera completamente racional, es decir, que el objeto de ese sentimiento corresponde, de manera especial, a algún tipo de disposición innata o adquirida. Tal disposición, por ejemplo, se expresa en el afecto de la madre hacia su hija, que es instintivo. O puede manifestarse en el dolor de la madre ante la cuna vacía de su hija, que es adquirido.

La existencia de una actitud sentimental indica que hay motivos para la acción de los cuales el individuo no es plenamente consciente o sobre los cuales tiene apenas un control parcial. Cada sentimiento tiene una historia, ya sea en la experiencia del individuo o en la de su raza, pero quien actúa guiado por él puede no estar consciente de tal historia.

Los intereses se dirigen no tanto hacia los objetos como hacia los fines que un objeto particular encarna. Por tanto, hablar de intereses implica la existencia de medios y una clara conciencia de la distinción entre medios y fines. Nuestros sentimientos se relacionan con nuestros prejuicios que pueden estar ligados a cualquier cosa personal, razas y cosas inanimadas. Los prejuicios se relacionan igualmente con los tabúes manteniendo de esta manera las "distancias sociales" y la organización social existente. Los sentimientos y los prejuicios son formas elementales del conservatismo mientras que los intereses son racionales, móviles y se orientan hacia el cambio.

El dinero es la herramienta cardinal por medio de la cual los valores se racionalizan y los sentimientos se reemplazan por el interés, y por ello puede convertirse en un medio valioso de intercambio puesto que no tenemos una actitud personal ni sentimental hacia él, como la que tenemos, por ejemplo, hacia nuestro hogar. Estaremos interesados en adquirir una cierta suma de dinero para lograr un determinado propósito, pero probablemente también estaremos igualmente satisfechos si ese fin es alcanzado por cualquier otro medio. Solamente el avaro se orienta sentimentalmente hacia el dinero y en tal caso preferirá un tipo particular el oro por ejemplo, independientemente de su valor. En 
este caso el valor del oro está determinado por el sentimiento personal antes que por la razón.

Una organización compuesta por individuos y grupos que compiten entre sí está en un estado de equilibrio inestable que sólo puede mantenerse gracias a un proceso de reajuste continuo. Este aspecto de la vida social y este tipo de organización social están representados por el mundo de los negocios, tema de investigación de la economía política.

La extensión de la organización industrial, basada en las relaciones impersonales definidas por el dinero, se ha desarrollado mano a mano con la incesante movilidad de la población. Bajo las condiciones de la vida urbana el obrero y el artesano, con su habilidad para realizar una tarea específica, se ven compelidos a moverse de una región a otra en busca del particular tipo de empleo para el cual están capacitados. La marea de la inmigración, que se desplaza hacia y desde Europa, en buena medida es un ejemplo de esta misma movilidad. ${ }^{10}$

De otra parte, a medida que las dificultades de comunicación y transporte decrecen, el comerciante, el manufacturero, el profesional y el especialista en cada vocación buscan su clientela en un área cada vez más amplia del territorio. Esta es otra forma de medir la movilidad de la población. Sin embargo, la movilidad de un individuo o de un grupo se calcula no solamente por el cambio de lugar sino por el número y variedad de estímulos a los cuales responde y, por tanto, no depende únicamente de los medios de transporte sino también de los de comunicación. La educación y la habilidad de leer y la extensión de la economía monetaria hacia un creciente rango de intereses vitales en la medida en que despersonalizan las relaciones sociales incrementan simultáneamente la movilidad de los pueblos modernos.

Los términos "movilidad" y "aislamiento" cubren un amplio rango de fenómenos y pueden representar simultáneamente tanto una característica como una condición. Así como el aislamiento puede deberse a la existencia de barreras físicas para la comunicación, a un peculiar temperamento o a una carencia de educación, así también la movilidad puede ser una consecuencia tanto de medios naturales de comunicación como de un tipo de educación que estimule maneras expansivas.

Hoy se reconoce que aquello que ordinariamente llamamos falta de inteligencia de individuos, razas y comunidades es frecuentemente un resultado del aislamiento y que la movilidad de una población es incuestionablemente un factor muy importante en su desarrollo intelectual.

Hay una íntima conexión entre la inmovilidad del hombre primitivo y su supuesta incapacidad para utilizar ideas abstractas. El conocimiento que ordinariamente posee un campesino sobre la naturaleza de su vocación es concreto y personal. Conoce individual y personalmente a cada miembro del rebaño que atiende. Con el transcurso de los años llega a estar tan ligado a la tierra que vive como pérdida personal el traslado desde su terruño hacia otro. Para un hombre así, el valle vecino, o aun la franja al otro extremo del villorrio, es, en cierto sentido, un territorio ajeno. Gran parte de la eficiencia del campesino como trabajador agrícola depende de esta relación íntima y personal con esa parcela que tiene a su cuidado y para lo cual ha sido educado. Por consiguiente, bajo estas condiciones, sólo una pequeña parte de

\footnotetext{
${ }^{10}$ Walter Bagehot, The Postulates of Political Economy, (London, 1885), pp. 7-8.
} 
su conocimiento práctico tomará la forma de una generalización científica, puesto que piensa en términos concretos y no necesita ningún otro tipo de noción.

Apelando a otro ejemplo, notamos cómo las características intelectuales de los judíos y su reconocido interés por las ideas abstractas y radicales están incuestionablemente ligados al hecho de que, ante todo, son gente de ciudad. El "Judío Errante" es una abstracción para describir los diversos escenarios en que se mueve. Su conocimiento del mundo se basa en identidades y diferencias, es decir, en análisis y clasificación. Criado en íntima asociación con el bullicio de los asuntos del mercado, constantemente emprende el astuto y fascinante juego de comprar y vender, en el cual emplea la más interesante de las abstracciones, el dinero. De esta manera no posee ni la oportunidad ni la inclinación a cultivar ese vínculo íntimo con lugares y personas tan característico de la persona inmóvil. ${ }^{11}$

La concentración de la población en las ciudades, la extensión de los mercados, la división del trabajo, la concentración de individuos y grupos en tareas específicas, han cambiado incesantemente las condiciones materiales de vida haciendo así necesarios los ajustes constantes a las nuevas situaciones. Al mismo tiempo, ha surgido un número de organizaciones especiales cuya existencia tiene el propósito de facilitar aquellos ajustes. El mercado, sobre cuya base se desarrollaron las ciudades modernas, es uno de esos instrumentos. Otro, más interesante aún, es la bolsa y la cámara de comercio, donde los precios se fijan constantemente en respuesta a informes sobre cambios en las condiciones económicas mundiales.

Tales informes, en tanto que se calcula que originarán reajustes, tienen el carácter de lo que llamamos noticia. Es la existencia de una situación crítica lo que convierte la información en noticia. Donde algo esté en juego, es decir, donde haya una crisis, la información que pueda afectar el resultado se convierte en "materia viva" como suelen decir los periodistas. Materia viva es noticia; materia muerta es mera información.

¿Cuál es la relación de la movilidad con la sugestión, la imitación, etc.?

¿Cuáles son los instrumentos prácticos que permiten que se incremente la sugestibilidad y la movilidad en una comunidad o en un individuo?

¿Existen condiciones patológicas en las comunidades que se asemejen a la histeria en los individuos? Si ello es así, ¿cómo se producen y cómo se controlan?

¿Hasta qué punto es la moda un indicador de movilidad?

¿Cuál es la diferencia en la manera como las modas y las costumbres se transmiten?

¿En qué consiste el malestar social y cuáles son las condiciones bajo las cuales se manifiesta?

¿Cuáles son las características de una comunidad progresiva y de una estática con respecto a su resistencia a las innovaciones?

\footnotetext{
${ }^{11}$ Cf. W.I.Thomas, Source Book of Social Origins, p. 169.
} 
¿Qué características mentales de los gitanos, de los 'hobos' y de los nómadas podrían encontrarse en la base de sus hábitos?

La bolsa de valores y la muchedumbre .- La bolsa de valores, que permite observar la fluctuación de los precios en respuesta a las noticias sobre las condiciones económicas en diferentes partes del mundo, es un ejemplo típico de ajuste. Reajustes similares tienen lugar en todos las parcelas de la vida social donde, sin embargo, los instrumentos para llevarlos a cabo no son tan perfectos. Por ejemplo, las publicaciones comerciales y profesionales, que informan a las profesiones y al comercio sobre nuevos métodos, experiencias e instrumentos, sirven para mantener actualizados a los miembros de tales profesiones y actividades, es decir, facilitan los reajustes a condiciones cambiantes.

Sin embargo, debe hacerse esta importante distinción: en los intercambios la competencia es más intensa, los cambios son más rápidos y, en lo que compete a los individuos, más importantes. Una forma de organización social tan móvil como la muchedumbre muestra una relativa estabilidad en contraste con la constelación de fuerzas del mercado, donde los competidores se encuentran para comprar y vender.

Es bien sabido que los factores decisivos en el movimiento de las muchedumbres y en la fluctuación de los mercados son psicológicos. Esto significa que entre los individuos que conforman las muchedumbres, o entre quienes participan en los movimientos mercantiles, existe una condición de inestabilidad que corresponde a lo que ha sido definido como crisis. En ambos casos las circunstancias que se viven son críticas, es decir, las tensiones son tales que una ligera causa puede precipitar un efecto gigantesco gracias a lo que, eufemísticamente, se ha llamado "momento psicológico

Estos momentos psicológicos pueden surgir en cualquier situación, pero usualmente ocurren en una sociedad que ha adquirido un alto estado de movilidad. Suceden con mayor frecuencia en sociedades donde la educación es general, donde los ferrocarriles, el telégrafo y los medios impresos han llegado a ser parte indispensable de la economía, es decir, en las ciudades más que en las pequeñas comunidades. Así, para quienes participan en la multitud y en el mercado, cada momento es "psicológico".

Podríamos decir que las crisis son la condición normal del intercambio. Las llamadas crisis financieras son apenas una extensión de las condiciones críticas que afronta la comunidad de negocios. Los pánicos financieros, que a veces siguen a las crisis financieras, son un precipitado de esta condición crítica.

El aspecto más fascinante del estudio de las muchedumbres y de las crisis económicas es que, en la medida en que se deben a causas psicológicas, es decir, en la medida en que son el resultado de la movilidad de las comunidades en las cuales ocurren, pueden ser controladas. Hay ejemplos suficientes de manipulación de las transacciones que ocurren en el mercado de valores $y$, aunque la evidencia sobre manipulación de las multitudes es menos accesible, podemos no obstante, señalar algunos casos: los sindicatos han desarrollado una técnica muy precisa para la instigación y el control de las huelgas; el Ejército de Salvación ha diseñado un libro de tácticas dedicado ampliamente al manejo de los grupos callejeros; y los profesionales del Evangelismo, como Billy Sunday, tienen una técnica muy elaborada para conducir sus encuentros.

En años recientes, bajo el título de psicología colectiva, se ha escrito mucho sobre las multitudes y los fenómenos similares de la vida social. La mayor parte de estos escritos se 
basan en observaciones generales pero no existen tratados sistemáticos. Los métodos prácticos que personas prácticas como el jefe político, el dirigente sindical y el especulador de la bolsa han elaborado para el control y manipulación del público, suministran un cuerpo de información a partir del cual es posible hacer un estudio más detallado y cercano de la conducta colectiva.

La ciudad, y particularmente la gran ciudad es, en sentido estricto, un laboratorio para la investigación de la conducta colectiva. Allí, más que en cualquier otro lugar, las relaciones humanas tienden a ser impersonales y racionales, definidas en términos de interés y de dinero. Las huelgas y los movimientos revolucionarios menores son endémicos en el ambiente urbano. Las ciudades, y particularmente las grandes ciudades, están siempre en equilibrio inestable y, como resultado, las grandes agregaciones, tan casuales y móviles, que constituyen nuestras poblaciones urbanas están en un estado de permanente agitación, barridas por cada nuevo viento de doctrina, sometidas a constantes alarmas y, en consecuencia, en una crónica condición de crisis.

Lo que hasta ahora se ha dicho muestra ante todo la importancia de un estudio más detallado y fundamental de la conducta colectiva. Las preguntas que siguen tal vez sugieran líneas de investigación que podrían ser exploradas fructíferamente por los estudiosos de la vida urbana.

¿Cuál es la psicología de la crisis? ¿Cuál es el ciclo de eventos involucrados en la evolución de una crisis, económica o política?

¿En qué medida el sistema parlamentario y electoral puede concebirse como un intento para "regular" las revoluciones y enfrentar y controlar las crisis?

¿Hasta qué punto la violencia pandillera, las huelgas y los movimientos políticos radicales son el resultado de las mismas condiciones generales que provocan el pánico financiero, el boom de los bienes raíces y los movimientos masivos de la población?

¿Hasta qué punto tanto el equilibrio inestable como el fermento social se deben a la velocidad de los cambios económicos tal como se reflejan en el mercado?

¿Cuáles son los efectos de la ampliación de los medios de comunicación sobre las fluctuaciones en el mercado y en los cambios económicos?

¿Acaso la escala de intercambios tiende a exagerar las fluctuaciones en el mercado o a estabilizarlo?

¿Los informes periodísticos, por la forma como presentan los hechos, tienden a acelerar los cambios sociales o a estabilizar el movimiento ya existente?

¿Cuál es el efecto de la propaganda y del rumor allí donde no existen fuentes de información confiables?

¿Hasta qué punto pueden controlarse las fluctuaciones del mercado mediante regulaciones formales?

¿Hasta qué punto pueden controlarse los cambios sociales, las huelgas y los movimientos revolucionarios mediante la censura? 
¿Hasta qué punto la previsión científica de los cambios económicos y sociales puede ejercer control sobre la tendencia de los precios y de los eventos sociales?

¿Hasta qué punto podemos comparar el informe de precios que presenta la bolsa con el informe de la opinión pública que presentan los periódicos?

¿Hasta qué punto puede la ciudad, que responde más rápida y decisivamente a los eventos cambiantes, mirarse como el centro nervioso de la organización social?

\section{Relaciones secundarias y control social}

En los últimos años los métodos modernos de transporte y comunicación —el tranvía eléctrico, el automóvil, el teléfono, el radio- han alterado, silenciosa y rápidamente, la organización social e industrial de la ciudad moderna, han permitido concentrar el tráfico en los distritos de negocios y han cambiado por completo el comercio al detal multiplicando los suburbios residenciales y haciendo posible la aparición de los almacenes por departamentos. Estos cambios de la organización industrial y de la distribución de la población, han estado ligados a cambios en los hábitos, sentimientos y carácter de la población urbana.

La naturaleza de estos cambios está indicada por el hecho de que el desarrollo de las ciudades se ha visto acompañado por la sustitución de las relaciones directas, "primarias", cara a cara, por relaciones "secundarias", indirectas.

Por grupos primarios entiendo aquéllos que se caracterizan por asociación y cooperación personal, cara a cara. Son primarios en varios sentidos, pero fundamentalmente en la formación de la naturaleza social y de los ideales del individuo. El resultado psicológico de tal asociación personal e íntima es una cierta fusión de las individualidades en un todo, de tal manera que el yo de cada uno, al menos para muchos propósitos, se confunde con la vida y los propósitos del grupo. Quizá la forma más simple de describir esta totalidad es diciendo que es un "nosotros", es decir, que implica aquel tipo de compromiso e identificación mutua que se expresa naturalmente con dicha palabra. Se vive en el sentimiento de ese todo y se dirige la voluntad hacia ese sentimiento. ${ }^{12}$

El contacto físico, el tacto y la vista, es la base de las relaciones humanas más elementales. Madre e hijo, esposo y esposa, padre e hijo, amo y sirviente, parentesco y vecindad, ministro, médico y maestro, tales son las relaciones más íntimas y reales de la vida y, en las pequeñas comunidades, son prácticamente inclusivas.

Las interacciones que tienen lugar entre los miembros de una comunidad así constituida son inmediatas. La interacción se desenvuelve en el terreno del instinto y del sentimiento. El control social surge de manera espontánea respondiendo directamente a las influencias personales y al sentimiento colectivo y es, por tanto, el resultado del acuerdo personal más que de la formulación de un principio racional y abstracto.

Iglesia, escuela y familia.-En la gran ciudad, donde la población es inestable, donde padres e hijos trabajan fuera de casa y a menudo en partes lejanas, donde miles de personas viven lado a lado por años sin tener un contacto cercano, las relaciones íntimas

\footnotetext{
${ }^{12}$ Charles Horton Cooley, Social Organization, p.15.
} 
propias de los grupos primarios se debilitan y el orden moral en el cual descansan se disuelve gradualmente.

Bajo la influencia desintegradora de la vida urbana, la mayoría de nuestras instituciones tradicionales la iglesia, la escuela y la familia se han modificado enormemente. La escuela, por ejemplo, ha asumido algunas de las funciones de la familia: un nuevo espíritu de comunidad y de vecindad tiende a organizarse alrededor de la escuela pública para defender el bienestar moral y físico de los niños.

La iglesia, que ha perdido buena parte de su influencia desde el momento en que el papel impreso tomó el lugar del púlpito en la interpretación de la vida, parece estar hoy en día en proceso de reajuste a las nuevas condiciones.

La iglesia, la escuela y la familia debieran ser estudiadas desde el punto de vista de este reajuste a las condiciones de la vida urbana.

¿Qué cambios han sucedido recientemente en los sentimientos familiares, en las actitudes de los esposos hacia sus esposas, de ellas hacia ellos, de los niños hacia sus padres?

¿Qué nos enseñan los informes de las cortes juveniles sobre estos temas?

¿En qué terrenos de la vida social se observan los mayores cambios en las costumbres familiares?

¿En qué medida estos cambios han tenido lugar como respuesta a las influencias del ambiente urbano?

Similarmente, es necesario adelantar investigaciones sobre la iglesia y la escuela. Aquí, también, hay una actitud diferente y nueva como respuesta a un ambiente nuevo. Este trabajo es importante pues es en estas instituciones en las cuales los intereses inmediatos y vitales de la vida encuentran una expresión corporativa donde descansa, en último análisis, la organización social.

Probablemente el rompimiento de los lazos locales, bajo la influencia del ambiente urbano, y el debilitamiento de las coerciones e inhibiciones del grupo primario son responsables de la creciente ola de vicio y crimen en las grandes ciudades. Sería interesante, entonces, determinar en qué medida el aumento de la criminalidad tiene una relación directa con la creciente movilidad de la población y en qué medida ésta es una función del crecimiento de la población. Es desde este punto de vista que debiéramos interpretar las estadísticas que registran la desintegración del orden moral, por ejemplo aquéllas que nos muestran los datos sobre divorcios, ausentismo escolar y crimen.

¿Qué efecto tiene la pertenencia a un hogar propio sobre el ausentismo, el divorcio y el crimen?

¿En qué regiones y clases ciertos tipos de crímenes son endémicos?

¿En qué clases ocurren divorcios con mayor frecuencia? ¿Cuál es la diferencia entre campesinos $y$, digamos, actores? 
¿En qué medida en un grupo racial dado por ejemplo, entre los italianos en New York o los polacos en Chicago viven padres e hijos en el mismo mundo, hablan el mismo lenguaje y comparten las mismas ideas, y en qué proporción estos hechos dan cuenta de la delincuencia juvenil?

¿Hasta dónde las costumbres hogareñas son responsables de las manifestaciones criminales de un grupo inmigrante?

Las crisis y los tribunales. - Es característico de la vida urbana que toda clase de gente se relacione entre sí aunque nunca se entienda del todo. El anarquista y el hombre de club, el sacerdote y el levita, el actor y el misionero que tocan sus codos en la calle, viven sin embargo en mundos totalmente diferentes. Tan grande es la segregación entre estos grupos vocacionales que es posible, dentro de los límites de la ciudad, vivir en un aislamiento comparable al de alguna remota comunidad rural.

Walter Besant nos cuenta la siguiente anécdota de su experiencia como editor del People 's Palace Journal:

En mi calidad de editor me propuse estimular el esfuerzo literario con la esperanza de descubrir algún genio desconocido y latente. Los lectores del Journal eran miembros del sector educando del lugar. En su mayoría eran empleados jóvenes algunos de ellos muy buenos muchachos. Habían formado un grupo de debates al cual asistía yo de vez en cuando. Pero, jay! sus debates se desarrollaban en la ignorancia más profunda, en la mayor inconsciencia pero con la mayor satisfacción. Me propuse persuadirlos de que era deseable, al menos, analizar los hechos de cada caso antes que hablaran; en vano les sugerí temas para sus ensayos y hasta les ofrecí premios por sus versos. Descubrí, con sorpresa, que entre esos miles de jóvenes, chicos y chicas, no era posible descubrir el menor indicio, por rudimentario que fuera, de capacidad literaria. En otros sitios hay jóvenes que nutren sus ambiciones literarias con alguna habilidad. Pero, ¿cómo podría haberlos aquí sin libros, sin periódicos, sin revistas y sin bibliotecas públicas? ${ }^{13}$

En las colonias de inmigrantes que se han establecido en todas las grandes ciudades, los extranjeros viven en un aislamiento que, aunque diferente al del East London, es sin embargo mayor.

La diferencia radica en que cada una de estas pequeñas colonias tiene, en mayor o menor grado, su propia independencia política y organización social y es el centro de una propaganda nacionalista más o menos vigorosa. Por ejemplo, cada uno de estos grupos tiene uno o más periódicos impresos en su propio idioma. En Nueva York había, hace unos pocos años, 270 publicaciones en 23 idiomas diferentes y apoyados por las comunidades locales. En Chicago había 19 diarios en 7 idiomas extranjeros con una circulación de 368.000 ejemplares.

Bajo estas condiciones, los ritos sociales y el orden moral que los inmigrantes trajeron de sus países, han tenido éxito frente a las influencias del ambiente americano. Sin embargo, en la segunda generación este control social, basado en las costumbres del hogar, tiende a desaparecer.

\footnotetext{
${ }^{13}$ Walter Besant, East London, p. 13.

Digitalizado por RED ACADEMICA
} 
Podemos, entonces, decir que el ambiente urbano intensifica todos los efectos de la crisis.

El término "crisis" no lo entendemos en su acepción violenta; implica cualquier alteración del hábito. Hay crisis en la vida del joven cuando deja su hogar. Los negros emancipados y los campesinos europeos inmigrantes son grupos en crisis. Cualquier crisis tiende hacia tres cambios posibles: mayor adaptación, eficacia reducida o muerte. En términos biológicos "sobrevivir" representa un ajuste exitoso a la crisis, acompañado típicamente de una modificación en la estructura. Para los seres humanos, significa estímulo mental y mayor inteligencia o depresión en caso de descalabro. ${ }^{14}$

Bajo las condiciones impuestas por la vida urbana, donde los individuos y los grupos ya no se rigen por la simpatía común o por la comprensión mutua pero viven juntos bajo relaciones de interdependencia aunque ya no de intimidad, las condiciones del control social se ven alteradas en gran medida y las dificultades se aumentan.

El problema así creado se cobija usualmente bajo el nombre de "asimilación". Se asume que la razón que explica el rápido incremento del crimen en las grandes ciudades se debe al hecho de que los extranjeros no han tenido éxito en asimilarese a la cultura americana y no se adaptan a sus costumbres. Si ello fuera cierto, de por sí sería un descubrimiento interesante pero los hechos parecen sugerir que la verdad podría encontrarse en la dirección opuesta.

Uno de los hechos más importantes establecidos por la investigación se refiere al tema de los hijos americanos de los inmigrantes, la llamada "segunda generación". Los informes tomados de las sentencias condenatorias promulgadas por el Tribunal de Nueva York durante el período comprendido entre el lo. de octubre de 1908 y el 30 de junio de 1909 así como las reclusiones en las instituciones penales de Massachusetts sin contar las granjas estatales, durante el año que terminó el 30 de septiembre de 1909, forman la base para el análisis de las tendencias criminales de la segunda generación.

A partir de esta información aparece la tendencia clara a mostrar una diferencia en cuanto a la criminalidad observable en la primera y la segunda generación. También queda claro que esta diferencia es mucho más frecuente en la dirección de la criminalidad de los americanos hijos de no inmigrantes que en el sentido opuesto. Esto significa que la tendencia criminal de la segunda generación está lejos de la de los crímenes peculiares a los inmigrantes y se acerca a la de los americanos hijos de padres nativos. A veces este movimiento ha llevado la criminalidad de los grupos de segunda generación incluso más lejos que la de los hijos de padres nativos. Entre los grupos de segunda generación comparados, uno sólo mantiene una constante adherencia a la regla general que se ha mostrado anteriormente, mientras que todos los otros, en algún punto, no se comportan según ella. Este único grupo es el de los irlandeses de segunda generación. ${ }^{15}$

\footnotetext{
${ }^{14}$ William I. Thomas, «Race Psychology: Standpoint and Questionnaire with Particular Reference to (he Immigrant and Negro,» American Journal of Sociology, xvii (May, 1912), 736.

${ }^{15}$ Reports of the United States Immigration Commission, VI, 14-16. 
Lo que observamos, como resultado de la crisis, es que el control que se basaba anteriormente en las costumbres fue reemplazado por el control basado en las leyes positivas. Este cambio corre paralelo con el movimiento que indica que las relaciones secundarias han tomado el lugar de las primarias en el ambiente urbano.

Es característico de los Estados Unidos que los grandes cambios políticos sean efectuados experimentalmente bajo la presión de la agitación o a partir de la iniciativa de minorías, pequeñas pero militantes. No hay probablemente otro país en el mundo donde haya tantas "reformas" en marcha como hoy en día en los Estados Unidos. La reforma, en efecto, se ha convenido en un tipo de "depone casero". Las modificaciones así efectuadas, casi sin excepción, implican alguna clase de restricción o control gubernamental sobre las actividades que anteriormente eran "libres" o controladas únicamente por las costumbres y por la opinión pública. Esta ampliación de lo que se llama el poder policiaco ha producido un cambio no solamente en la administración de la ley sino también en el carácter de los tribunales.

Las cortes juveniles ilustran lo que probablemente está sucediendo en todas partes. En estos tribunales los jueces han asumido algunas de las funciones de los agentes administrativos, y sus deberes consisten menos en la interpretación de la ley que en prescribir soluciones y suministrar consejos para devolver a los delincuentes a sus lugares normales dentro de la sociedad.

Una tendencia similar a darle a los jueces una amplia discreción y a imponerles responsabilidades adicionales se manifiesta en aquellos tribunales que tienen que ver con los asuntos técnicos del mundo de los negocios, y en la creciente popularidad de comisiones, como la Comisión de Comercio Interestatal, donde se combinan funciones administrativas y judiciales.

Para interpretar de manera acertada los hechos que se relacionan con el control social es importante comenzar con una clara concepción de la naturaleza de la acción corporativa. Ésta comienza donde hay algún tipo de comunicación entre los individuos que constituyen un grupo. La comunicación puede tener lugar en diferentes niveles; es decir, puede haber estímulos muy leves que hallen respuesta en los niveles instintivo, sensomotor o psicomotor. El mecanismo de la comunicación es muy sutil, tan sutil que a veces es difícil concebir cómo tales estímulos son transmitidos de una mente a otra. Esto no implica que haya necesariamente alguna forma especial de conciencia, algún sentido especial de afinidad o pertenencia que explique la acción corporativa.

En efecto, como se ha mostrado para el caso de sociedades altamente organizadas y estáticas, como la de las hormigas, probablemente allí no tiene lugar nada que pudiéramos llamar comunicación.

Es un hecho comprobado que si una hormiga se saca de su hormiguero y posteriormente se devuelve a él no será atacada, mientras que, casi invariablemente, una hormiga que pertenezca a otro hormiguero sí lo será. El uso común ha creado palabras como memoria, amistad, enemistad para describir este hecho. Bethe hizo el siguiente experimento: colocó una hormiga en los fluidos extraídos de los cuerpos de insectos de su mismo hormiguero y no fue atacada; sin embargo, sí lo fue cuando se puso en los líquidos tomados de insectos de un hormiguero "hostil"16.

\footnotetext{
${ }^{16}$ Jacques Loeb, Comparative Physiology of the Brain, pp. 220-21.

Digitalizado por RED ACADEMICA
} 
Este otro ejemplo ilustra cómo la comunicación simple y automática puede realizarse en el nivel instintivo:

Una hormiga, cuando sale por primera vez de su hormiguero siempre retorna por el mismo camino. Esto demuestra que alguna huella ha dejado tras de sí que le sirve de guía para regresar. Si la hormiga retorna por este camino sin llevar carga, ninguna otra ensaya esta dirección. Pero si trae miel o azúcar, las otras emprenderán la misma senda. Por tanto, algún rastro de las sustancias que se llevan ha de permanecer en ella. Estas sustancias deben ser lo suficientemente fuertes para afectar químicamente a los insectos ${ }^{17}$.

Lo que aquí interesa señalar es que la acción corporativa es posible gracias a este recurso relativamente simple y que los individuos no solamente reaccionan entre sí de manera instintiva sino que inevitablemente comunican sus sentimientos, actitudes y excitaciones orgánicas $y$, al hacerlo, necesariamente reaccionan no solamente ante lo que cada uno hace sino ante lo que pretende, desea o espera hacer. El hecho de que los individuos a menudo revelan a otros sentimientos y actitudes de los cuales apenas tienen una leve conciencia es lo que hace posible que $A$ actúe sobre los motivos de $B$ tan pronto, o incluso antes de que $B$ entre en acción. Además, A puede actuar sobre los estímulos que emanan de $B$ sin que él mismo tenga una clara conciencia de cuál es la fuente de sus reacciones: tan sutiles e íntimas pueden ser las reacciones humanas que controlan a los individuos que están ligados entre sí por medio de procesos psicosociales. Para ser efectivo, cualquier tipo de control formal debe basarse en esa clase de control instintivo y espontáneo.

Para los propósitos de nuestra investigación, los cambios en la forma del control social podrían agruparse así:

1. La sustitución de la costumbre por la ley positiva y la extensión del control municipal a actividades que anteriormente se dejaban a la iniciativa individual.

2. La asignación a los jueces, en los tribunales municipales y criminales, de funciones administrativas de suerte que la administración de la ley criminal deja de ser una mera aplicación del ritual social y se convierte en una aplicación de métodos técnicos y racionales que requieren conocimiento especializado para restituir al individuo a la sociedad y reparar el daño causado.

3. Cambios y divergencias en las costumbres de los diferentes grupos urbanos aislados o segregados. Por ejemplo, ¿cuáles son las costumbres de las vendedoras, de los inmigrantes, de los políticos, de los agitadores laborales?

El objetivo de esta investigación debería consistir en distinguir no solamente las causas de estos cambios y la dirección en que ellos se mueven, sino también la fuerzas que tienden probablemente a minimizarlos o neutralizarlos. Por ejemplo, es importante saber silos motivos que multiplican las restricciones positivas de los individuos necesariamente irán tan lejos en este país como han ido en Alemania. ¿Producirán ellos condiciones próximas al socialismo?

${ }^{17}$ Ibid., p. 221. 
El vicio comercializado y el tráfico de licor.-El control social, bajo las condiciones anteriormente enumeradas, podría estudiarse en el intento por acabar con el vicio e intervenir el tráfico de licor.

Las tabernas y los establecimientos de vicio han existido como un medio de explotar los apetitos y los instintos fundamentales de la naturaleza humana, de ahí que los esfuerzos hechos por regular y suprimir estas formas de explotación y tráfico se conviertan en temas importantes de investigación.

Tal investigación debería estar basada en un completo estudio de: 1. la naturaleza humana sobre la cual se erige este tipo de comercio; 2 . las condiciones sociales que tienden a convertir los apetitos naturales en vicios sociales; 3 . los efectos prácticos de los esfuerzos por limitar, controlar y acabar con este tráfico y con el uso y venta de licor.

Entre las cosas que desearíamos saber están:
¿Hasta qué punto el apetito por los estímulos alcohólicos es una disposición prenatal?

¿Hasta qué punto puede tal instinto transferirse de una forma de estímulo a otra, es decir, por ejemplo, del whisky a la cocaína, etc.?

\begin{abstract}
¿Hasta qué punto es posible sustituir estímulos normales y saludables por estímulos patológicos?
\end{abstract}

\title{
¿Cuáles son los efectos morales y sociales de los vicios secretos?
}

Allí donde se establece un tabú tempranamente en la vida, ¿tiene el efecto de idealizar los frutos de la permisión? ¿Se produce este efecto en algunos casos pero no en otros? $\mathrm{Si}$ es así ¿cuáles son las circunstancias que determinan estos diversos caminos? ¿Pierden los hombres, de repente, el gusto por el licor u otros estimulantes? ¿Cuáles son las condiciones bajo las cuales esto sucede?

Muchas de estas preguntas sólo pueden responderse mediante el estudio de las experiencias individuales. Los vicios, indudablemente, tienen su historia natural, como ciertas formas de enfermedad. Pueden, entonces, mirarse como entidades independientes que encuentran su hábitat en el ambiente humano pero invariablemente exhiben, a través de los cambios, un carácter que les es típico.

En sus primeros días, el movimiento por la abstinencia del alcohol (temperante movement" ¿tuvo un carácter religioso y sus efectos fueron muy pintorescos. Recientemente, sus líderes han desplegado una estrategia más clara pero la lucha contra el tráfico del licor todavía tiene las características de un movimiento popular que, luego de conquistar los distritos rurales, busca ahora llegar a las ciudades.

La cruzada contra el vicio comenzó en aquellas ciudades, donde, de hecho, la comercialización del vicio fue fruto de procesos internos. La sola discusión de este tema en público ha significado un enorme cambio en las costumbres sexuales. Es significativo que este movimiento haya coincidido, en todas partes, con el ingreso de la mujer a una mayor libertad en las industrias, las profesiones, los partidos políticos. 
Hay condiciones peculiares de la vida en las grandes ciudades (a lo que nos referimos bajo el título de "Movilidad de la población de las grandes ciudades") que hacen especialmente difícil el control del vicio. Por ejemplo, las cruzadas y los movimientos religiosos generalmente no tienen el mismo éxito en el ambiente urbano que en las comunidades más pequeñas y heterogéneas. ¿Cuáles son las condiciones que nos permiten aseverar esto?

Quizá los hechos que más vale la pena estudiar en conexión con el movimiento por la supresión del vicio, son aquéllos que indican los cambios que, en los últimos cincuenta años, han tenido lugar en las costumbres sexuales, especialmente aquéllos que se refieren a la modestia o inmodestia en el vestir, a la conducta y a la libertad que hoy tienen los jóvenes para discutir los asuntos sexuales.

Parece, en efecto, que estuviéramos en presencia de dos tendencias que definen la época: la una destinada finalmente a poner el licor en la lista de las drogas nocivas, y la otra a levantar el tabú que, especialmente entre la gente anglosajona, había inhibido la discusión abierta de los temas sexuales.

Los partidos políticos y la publicidad.-En todas partes se observa una tendencia a incrementar el poder del brazo ejecutivo del gobierno a expensas del legislativo. La influencia de las legislaturas estatales y de los concejos municipales ha sido aminorada, en algunas instancias, mediante la introducción del referéndum y la revocatoria y, en otras, por la introducción de las comisiones. La razón más evidente para estos cambios es que ofrecen un medio para derrocar el poder de los políticos profesionales, pero la causa más profunda parece ser el reconocimiento de que la forma de gobierno que tuvo su origen en las asambleas populares se adecuaba a las necesidades de una pequeña comunidad basada en las relaciones primarias, pero no se ajusta al gobierno de las poblaciones heterogéneas y cambiantes de ciudades de tres o cuatro millones de habitantes.

Mucho de esto depende, por supuesto, del carácter y tamaño de la población. Allí donde encontramos una población homogénea y el número de votantes no es muy grande para la realización de discusiones calmadas y exhaustivas, no podría imaginarse un mejor método para manejar los asuntos públicos ni para evitar los chanchullos, las intrigas y el despilfarro y para estimular la vigilancia y alimentar el consenso. Sin embargo, cuando el tamaño de las asambleas populares excede las setecientas $u$ ochocientas personas $y$, aún más, cuando una buena porción de la población está formada por extranjeros, como irlandeses o francocanadienses, que muy recientemente han venido hacia Nueva Inglaterra, la institución funciona menos perfectamente puesto que la multitud es muy grande para debatir, las facciones tienden a ampliarse y los inmigrantes, no entrenados en el autogobierno, se convierten en presas fáciles de los pequeños demagogos. ${ }^{18}$

Con el desarrollo y organización de la vida urbana, los problemas del gobierno se han vuelto tan complejos que, sencillamente, no es deseable dejarlos bajo el control de hombres cuya única calificación consiste en que han tenido éxito en llegar a sus puestos públicos mediante la maquinaria clientelista.

Otra circunstancia que ha hecho que la selección de los funcionarios mediante el voto popular sea algo poco práctico en las circunstancias de la vida urbana, es que, salvo en

${ }^{18}$ James Bryce, The American Commonwealth, I, 566. 
casos especiales, el votante conoce poco o nada acerca de aquél por quien vota o conoce muy poco, o nada, sobre las funciones que desempeñará y, además, está muy ocupado para informarse acerca de las condiciones y necesidades de la ciudad como un todo.

En una elección reciente en Chicago, por ejemplo, los votantes fueron llamados a seleccionar candidatos entre 250 nombres, la mayoría de ellos desconocidos. Bajo estas circunstancias el ciudadano que desea votar inteligentemente confía en el consejo de alguna organización más o menos informada e interesada.

Para dar cuenta de estas circunstancias producidas fundamentalmente por las condiciones de la vida urbana, se han creado dos tipos de instituciones encargadas de controlar aquellas crisis artificiales que llamamos elecciones. Una de ellas es la organización representada por el jefe político y la maquinaria política; la otra por las ligas independientes de votantes, las asociaciones de contribuyentes y organizaciones como los consejos de investigación municipal.

Una prueba de las condiciones bastante primitivas en que se formaron nuestros partidos políticos es que siempre han buscado gobernar el país bajo el principio de que el remedio para todos los males de la administración es la "expulsión de los pícaros", como dice la frase popular. La maquinaria política y el jefe político han llegado a existir en interés de los partidos políticos organizados necesariamente para ganar las elecciones. La maquinaria política es apenas un instrumento técnico inventado para alcanzar tal objetivo y el jefe es el experto que la gobierna y por eso es tan indispensable para ganar una elección como el entrenador profesional para el éxito de un equipo de fútbol.

El primer tipo de organización, la máquina política, se basa, como un todo, en las relaciones locales y personales, es decir, en las relaciones primarias. La segunda, las organizaciones que luchan por un "buen gobierno" invocan al público y éste, en el sentido en que entendemos normalmente la expresión, es un grupo basado en relaciones secundarias pues, como regla, no está formado por relaciones de conocimiento estrecho entre sus miembros.

La maquinaria política es, en efecto, un intento por mantener, dentro de la organización administrativa de la ciudad, el control de un grupo primario. Las organizaciones así construidas, cuyo ejemplo clásico es Tammany Hall, parecen ser totalmente feudales en su carácter. Las relaciones entre el jefe y sus capitanes parecen descansar, precisamente, en la lealtad personal de un lado y la protección personal del otro, lo que implica la relación feudal. Las virtudes que tal organización invoca son aquéllas de la tribu: lealtad, fidelidad y devoción a los intereses del jefe y del clan. La gente que conforma la organización, sus amigos y patrocinadores, constituyen un grupo "nosotros", mientras que el resto de la ciudad es apenas el mundo exterior, que no se concibe como completamente vivo ni completamente humano en el sentido en que lo son los miembros del grupo "nosotros". De alguna manera nos aproximamos así a las condiciones de la sociedad primitiva.

La imagen de "sociedad primitiva" que tenemos en mente es la de los pequeños grupos esparcidos por el territorio. Su tamaño está determinado por las condiciones de la lucha por la existencia. Su organización interna corresponde a su tamaño. Un grupo de grupos puede tener alguna relación entre sí (parentesco, vecindad, alianza, connubium y commercium) que los agrupa y los diferencia de los otros. Así surge una diferenciación entre el grupo "nosotros", y cualquier otro cuerpo, el grupo "otros". Los miembros de un grupo "nosotros" están en una relación de paz, orden, ley, gobierno e industria entre sí. Su 
relación con los de afuera es de guerra y pillaje, salvo cuando un tratado modifica esta situación.

Las relaciones de camaradería y paz hacia el grupo "nosotros" y de hostilidad y guerra hacia el grupo "otros" son correlativas. La exigencia de guerra con los extraños es lo que produce la paz interior pues los conflictos internos debilitarían al grupo para emprender la guerra. Estas exigencias también fortalecen al gobierno y a la ley pues permiten prevenir las disputas y estimular la disciplina. ${ }^{19}$

En la mayoría de las grandes ciudades, la política ofrece material abundante para el estudio del tipo representado por el jefe político, así como de los mecanismos sociales creados para ser incorporados en la maquinaria política. Es necesario, sin embargo, que los estudiemos de manera desprevenida. Algunas de las preguntas que debiéramos resolver serían las siguientes:

¿Cuál es, en la práctica, la organización política de la ciudad? ¿Cuáles son los sentimientos, actitudes e intereses que encuentran expresión a través de ella?

¿Cuáles son los instrumentos prácticos que emplea para movilizar sus fuerzas y ponerlas en acción?

¿Cuál es el carácter de la convocatoria partidista en las diferentes regiones culturales que conforman la ciudad?

¿Qué parte del interés en la política es práctica y qué otra es puramente lúdicá?

¿Qué parte del costo de las elecciones se va en propaganda? ¿Hasta qué punto dicha propaganda se podría clasificar como "publicidad educativa" o como puro soborno?

¿Hasta qué punto pueden controlarse las elecciones por medios puramente técnicos, por catálogos, por procesiones de antorchas u oradores entrenados, en las condiciones actuales de las grandes ciudades?

¿Qué efecto tendrá la introducción del referéndum y de la revocatoria sobre los métodos electorales?

Publicidad y control social.-En contraste con la maquinaria política, que basa su acción organizada en los intereses locales, personales e inmediatos de los diversos grupos de vecinos y localidades, las organizaciones que luchan por la administración eficiente, los consejos de investigación municipal y similares buscan representar los intereses de la ciudad como un todo y para ello apelan a una opinión que no es ni local ni personal. Estas organizaciones pretenden garantizar la eficiencia y la buena administración gracias a la educación de los votantes, es decir, investigando y dando a conocer los hechos que conciernen al gobierno.

De esta forma, la publicidad ha llegado a ser una forma reconocida de control social y una profesión con una técnica elaborada que cuenta con el apoyo de un cuerpo especializado de conocedores.

\footnotetext{
${ }^{19}$ Sumner, Folkways, p. 12.
} 
El importante papel que desempeña la publicidad en la economía es uno de los fenómenos característicos de la vida urbana de una sociedad fundada en las relaciones secundarias.

En los últimos años, las personas y organizaciones que han tenido que ver con el público, es decir, el público fuera de las fronteras de las comunidades más pequeñas e íntimas, han tenido también su agente de prensa que a menudo es un diplomático acreditado ante los periódicos y ante el mundo entero antes que un publicista. Instituciones como la Russell Sage Foundation, y en menor medida, el General Education Board han buscado influenciar a la opinión pública directamente a través del medio publicitario. El informe Carnegie sobre educación médica, el estudio Pittsburgh, el informe de la Fundación Russell Sage sobre costos comparativos de la educación en escuelas públicas en varios estados son, además de informes científicos, formas elevadas de periodismo que examinan las condiciones existentes de manera crítica y buscan, a través de las agencias de publicidad, producir reformas radicales. El trabajo de la Oficina de Investigación Municipal de Nueva York ha tenido un propósito práctico similar. A esto debe añadirse el trabajo desarrollado por las exposiciones sobre salud infantil, a partir de encuestas realizadas en diferentes partes del país, y por propaganda análoga en favor de la salud pública.

Como una forma de control social, la opinión pública ha llegado a ser importante en sociedades fundadas en relaciones secundarias, cuyo tipo principal son las grandes ciudades. En ellas cada grupo social va creando su propio ambiente y, en la medida en que éste se vuelve estable, las costumbres tienden a acomodarse a las condiciones así creadas. En los grupos secundarios y en la ciudad, la moda desplaza a la costumbre y la opinión pública se convierte en la fuerza dominante para el control social.

Cualquier intento por entender la naturaleza de la opinión pública y su relación con el control social debe considerar ante todo las agencias e instrumentos que se han convertido en medios prácticos para controlarla, educarla o valerse de ella. El más importante de tales medios es la prensa, es decir, los periódicos y otras formas de literatura, por ejemplo, los libros populares. ${ }^{20}$

Adicionalmente tenemos las campañas educacionales para mejorar las condiciones de salud, las exposiciones sobre bienestar infantil y los diversos medios de "propaganda social" que se emplean ahora, a veces bajo la iniciativa de sociedades privadas, o de periódicos y revistas populares, para educar al público y animarlo a que se involucre en el movimiento por la mejora de las condiciones de vida comunitaria.

El periódico es el gran medio de comunicación de la ciudad, y la opinión pública se apoya en la información por él suministrada. La función principal del periódico es la que anteriormente estaba asignada al chisme popular.

Sin embargo, a pesar del cuidado con que los periódicos tratan de establecer los hechos de interés, no pueden competir con el chisme como medio de control social puesto que los periódicos mantienen algunas reservas no aceptadas por aquél. Por ejemplo, la vida privada de un individuo es un tema tabú para la prensa a menos que se convierta en una figura visible y cometa algún acto que manifiestamente lo coloque a la luz pública. No sucede lo mismo con el chisme especialmente porque en una pequeña comunidad ningún individuo es tan oscuro que sus asuntos privados escapen a la observación y discusión.

\footnotetext{
${ }^{20}$ Cf. Bryce, The American Commonwealth, p. 267.

Digitalizado por RED ACADEMICA
} 
En las pequeñas comunidades siempre existe alguna buena dosis de información personal interesante que fluye de cada individuo. La ausencia de esta característica es lo que permite, en buena medida, que la ciudad sea lo que es.

Algunos de los interrogantes que surgen sobre la naturaleza y función de los periódicos y de la publicidad son:

\section{¿Qué es noticia?}

¿Cuáles son los métodos y motivos del hombre de prensa? ¿Son los del artista, del historiador o simplemente los del comerciante?

¿Hasta qué punto la prensa controla o es controlada por el sentimiento público?

¿Qué es "fraude" y por qué lo es?

¿Qué es el periodismo amarillo y por qué es así?

¿Cuál sería el resultado de convertir a la prensa en monopolio municipal? ¿Cuál es la diferencia entre noticia y publicidad?

\section{Temperamento y medio urbano}

Las ciudades grandes han sido siempre el crisol de razas y culturas. Aparte de las interacciones vívidas y sutiles que ocurren en ellas, se han vuelto el fermento de nuevos tipos sociales. Las grandes ciudades de los Estados Unidos han sacado a grandes masas de campesinos del aislamiento de sus poblaciones nativas de Europa y América y, bajo el impacto de los nuevos contactos, las energías latentes de estos pueblos primitivos se han liberado y un sutil proceso de interacción ha dado nacimiento no solamente a nuevos tipos ocupacionales sino también temperamentales.

Movilización del individuo.-El transporte y la comunicación han producido, entre otros cambios quizá más silenciosos pero más profundos, lo que he dado en llamar "la movilización del individuo". Han multiplicado sus oportunidades de contacto y asociación con otros, pero de manera más transitoria e inestable. Una gran parte de la población de las grandes ciudades, inclusive quienes han construido sus hogares en campamentos y edificios de apartamentos, vive de manera similar a quien lo hace en algún gran hotel, encontrándose con los otros pero no conociéndose entre sí. Así las asociaciones más íntimas y permanentes de las pequeñas comunidades dan paso a relaciones más fortuitas y casuales.

Bajo estas circunstancias la posición del individuo está determinada, en grado considerable, por signos convencionales — la moda y el "frente" - y el arte de la vida se reduce en gran medida a patinar sobre superficies quebradizas y a aprender cuidadosamente los estilos y las formas sociales.

El transporte, la comunicación y la segregación de la población urbana tienden a facilitar la movilidad del individuo. El proceso de segregación establece distancias morales que convierte a la ciudad en un mosaico de pequeños mundos que se tocan pero no se interpenetran, permitiendo así que el individuo pase rápidamente de un medio moral a otro, y estimulando el fascinante pero peligroso experimento de vivir al mismo tiempo en varios mundos diferentes pero contiguos que de otra forma estarían completamente separados. Todo ello tiende a dar a la vida urbana un carácter superficial y adventicio; a 
complicar las relaciones sociales y a producir nuevos y divergentes tipos individuales. Introduce, al mismo tiempo, un elemento de aventura que se añade al estímulo propio de la vida urbana y proporcionan, para nervios frescos yjóvenes, un peculiar atractivo. La seducción de las grandes ciudades es, quizá, una consecuencia de estímulos que actúan directamente sobre los reflejos, de suerte que la conducta humana en este caso puede explicarse como una suerte de tropismo, similar a la atracción que la llama ejerce sobre la polilla.

Sin embargo, la atracción de la metrópolis se debe, en parte, al hecho de que en el largo plazo todo individuo encuentra entre las manifestaciones variadas de la vida urbana un tipo de ambiente en el cual expandir sus sentimientos de manera fácil; encuentra, en resumen, el clima moral en el cual su naturaleza particular obtiene los estímulos para convertir sus disposiciones innatas en expresiones plenas y libres. Pienso que son motivos de esta clase, basados no en el interés ni incluso en el sentimiento sino en algo más fundamental y primitivo, lo que saca a muchos jóvenes de la seguridad de sus hogares en el campo y los lleva a la enorme, ruidosa y excitante confusión de la vida urbana. En una pequeña comunidad el hombre normal, el hombre carente de excentricidad y genio, es quien tiene la probabilidad de éxito. La pequeña comunidad a veces tolera la excentricidad; la ciudad la premia. Ni el criminal, ni el anormal, ni el genio tienen la misma oportunidad para desarrollar sus disposiciones innatas en un pueblo; en la gran ciudad invariablemente la encuentran.

Hace cincuenta años todo poblado tenía una o dos personalidades excéntricas que eran tratadas ordinariamente con benevolente tolerancia, pero cuya propuesta de vida se miraba como impracticable o curiosa. Estos individuos excepcionales vivían una existencia aislada que, merced a sus excentricidades ya fuesen de genios o de anormales, los alejaba de cualquier relación íntima con sus coterráneos. Si eran criminales, las coerciones e inhibiciones de la pequeña comunidad los dejaban sin castigo. Si poseían la materia prima del genio permanecían estériles por falta de oportunidades. La historia que cuenta Mark Twain en Pudd'n Head Wilson es la descripción de uno de estos genios oscuros y carentes de aprecio. Ya no es cierto que

\section{Entre muchas nace una flor enrojeciéndose oculta}

Y derrocha su fragancia en la desértica atmósfera.

Como lo dijera Gray en su "Elegy in a Country Churchyard" antes del surgimiento de la metrópolis moderna.

En la ciudad muchos de estos tipos divergentes encuentran un medio en el cual, para bien o para mal, sus disposiciones y talentos germinan y fructifican.

En la investigación de estos tipos excepcionales y psicológicos que la ciudad ha producido deberíamos tratar de distinguir, tanto como fuera posible, entre aquellas cualidades mentales y abstractas que dan pie a la excelencia técnica y aquellas características más fundamentales que encuentran expresión en el temperamento. Por tanto, podemos preguntarnos:

¿Hasta qué punto las cualidades morales de los individuos se basan en su carácter nativo? ¿Hasta qué punto son hábitos convencionalizados impuestos por o extraídos de su grupo? 
¿Cuáles son las características y cualidades nativas sobre las cuales se basa el carácter moral o inmoral aceptado y convencionalizado por el grupo?

¿Qué conexión o divorcio parece existir entre las cualidades morales y mentales de los grupos y de los individuos que los conforman?

¿Son los criminales, por regla general, de un bajo nivel intelectual? Si es así, ¿qué tipo de inteligencia está asociado con los diferentes tipos de crimen? Por ejemplo

¿los ladrones profesionales y los individuos en quienes está depositada la confianza pública representan tipos mentales diferentes?

¿Cuáles son los efectos que tienen el aislamiento y la movilidad, el estímulo y la represión sobre estos tipos sociales?

¿Hasta qué punto los juegos de campo y otras formas de recreación proveen estímulos que de otra forma hallarían expresión en los vicios?

¿Hasta qué punto la orientación vocacional puede ayudar a las personas a encontrar actividades en las que puedan hallar libre expresión sus cualidades temperamentales?

La región moral.-Es inevitable que quienes buscan la misma clase de diversión, ya sea suministrada por una carrera de caballos o una ópera, se encuentren de vez en cuando en los mismos lugares. Como resultado, en la organización que la vida urbana asume espontáneamente, la población tiende a segregarse, no solamente de acuerdo a sus intereses, sino en concordancia con sus gustos y temperamentos. La distribución de la población que resulta de allí probablemente es muy diferente de la que producen los intereses ocupacionales o las condiciones económicas.

Todo vecindario, bajo las influencias que tienden a distribuir y segregar a la población urbana, puede asumir el carácter de una "región moral". Tal el caso de los vicedistritos que se encuentran en la mayoría de las ciudades. Una región moral no es necesariamente un lugar de residencia; puede ser apenas un punto de reunión, un lugar de veraneo.

Para entender las fuerzas que en todas las grandes ciudades tienden a desarrollar estos ambientes separados en los cuales los impulsos errabundos y reprimidos, las pasiones, los ideales se emancipan del orden moral dominante, es necesario referirse a la teoría de los impulsos latentes.

El hombre viene al mundo con todas las pasiones, instintos y apetitos incontrolados e indisciplinados. La civilización, en interés del bienestar común, demanda a veces la supresión y siempre el control de estas disposiciones naturales y salvajes. En el proceso de imponer su disciplina sobre el individuo, en hacer al individuo en consonancia con el modelo comunitario aceptado, muchos de esos impulsos se suprimen y muchos otros encuentran apenas una expresión indirecta en formas que son socialmente apreciadas o inocuas. Es en este punto que el deporte, la danza y el arte funcionan pues permiten que el individuo se purifique a sí mismo de estos impulsos salvajes, mediante medios simbólicos de expresión. Esta es la catarsis sobre la que escribió Aristóteles en su Poética, y que ha tomado nuevo y más importante significado gracias a las investigaciones de Sigmund Freud y al psicoanálisis. 
Sin duda muchos otros fenómenos sociales como las huelgas, las guerras, las elecciones populares y los movimientos religiosos realizan una función similar para liberar las tensiones subconscientes. Pero en las comunidades pequeñas, donde las relaciones sociales son más íntimas y las inhibiciones más imperativas, hay muchos individuos excepcionales que no encuentran en los límites de la actividad comunal una forma normal y saludable para desplegar sus aptitudes individuales y su temperamento.

Las "regiones morales" surgen debido, en parte, a las restricciones que la vida urbana impone y, en parte, a las licencias que ella misma ofrece. Hasta hace muy poco le dábamos mucha importancia a las tentaciones de la vida urbana pero no le hemos dado igual importancia al efecto de las inhibiciones y supresiones de los impulsos naturales e instintivos bajo las condiciones de la vida metropolitana. Para sólo mencionar un ejemplo, los niños, que en el campo se cuentan como bienes, en la ciudad se vuelven responsabilidades. Es mucho más difícil levantar una familia en la ciudad que en la granja. El matrimonio tiene lugar más tarde en la ciudad y a veces no tiene lugar en absoluto. Estos hechos producen consecuencias cuyos alcances aún no podemos evaluar completamente.

La investigación de los problemas considerados bien podría comenzar con el estudio de los tipos característicos de organización social que existen en las diferentes regiones mencionadas.

¿Cuál son los hechos externos que se relacionan con la vida bohemia, el trabajo temporal, los distritos de tolerancia, y otras "regiones morales" menos pronunciadas en su carácter?

¿Cuál es la naturaleza de las vocaciones que se conectan con la vida ordinaria de estas regiones? ¿Cuáles son los tipos mentales característicos que se sienten atraídos por la libertad que ellas ofrecen?

\section{¿Cómo se adaptan los individuos a estas regiones? ¿Cómo escapan de ellas?}

¿Hasta qué punto dichas regiones son el producto de la licencia o de las restricciones impuestas por la vida urbana a la naturaleza humana?

Temperamento y contagio social._-El contagio social tiende a estimular las diferencias temperamentales comunes en diferentes tipos y a suprimir aquellas características que los unirían a los tipos normales que los rodean, lo que concede especial importancia a la segregación del pobre, del vicioso, del criminal y de las personas excepcionales característica esta de la vida urbana. La asociación con otros de su propia índole suministra no solamente un estímulo, sino un apoyo moral para los rasgos que tienen en común y que no encontrarían en otra parte de la sociedad. En la gran ciudad el pobre, el vicioso y el delincuente, empujados a una intimidad contagiosa se reproducen incesantemente, en cuerpo y alma.

Debemos aceptar hasta cierto punto, como parte natural y normal de la vida urbana, estas "regiones morales" y a la gente más o menos excéntrica y excepcional que las habita.

No se debe entender por "región moral" un lugar de la sociedad que necesariamente es criminal o anormal. Al contrario, se aplica a ámbitos en donde prevalece un código moral divergente puesto que quienes la habitan están dominados de manera excepcional por el gusto o por la pasión o por algún interés que tiene sus raíces directamente en la 
naturaleza original del individuo. Puede ser un arte como la música, o un deporte como las carreras de caballos. Tal región difiere de otros grupos sociales debido a que sus intereses son más inmediatos y fundamentales. Por esta razón sus diferencias probablemente se deban más a un aislamiento moral que intelectual.

Debido a las oportunidades que otorga a los individuos excepcionales o anormales, la gran ciudad tiende a mostrar a la vista publica de manera masiva todos los tipos humanos y rasgos que ordinariamente estarían oscurecidos o suprimidos en las pequeñas comunidades. La ciudad, en síntesis, ofrece todo lo bueno y lo malo que hay en la naturaleza humana. Es este hecho, tal vez, más que cualquiera otro, lo que justifica el punto de vista que la concibe como un laboratorio en el cual la naturaleza humana y los procesos sociales pueden estudiarse de forma más conveniente. 